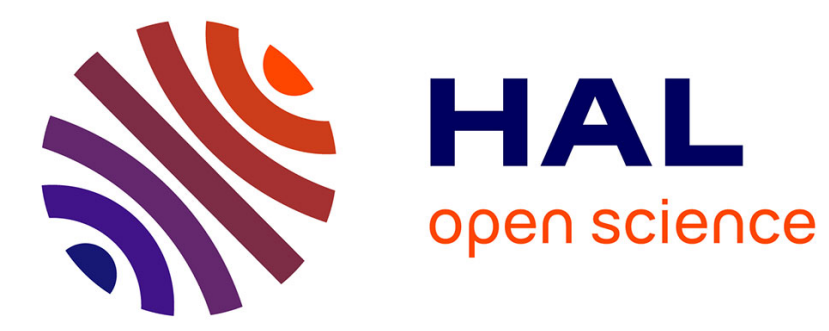

\title{
Sur un topos romanesque oublié : les scènes de banquets
}

Corinne Jouanno

\section{To cite this version:}

Corinne Jouanno. Sur un topos romanesque oublié: les scènes de banquets. Revue des Etudes Grecques, 1996, 109 (1), pp.157-184. 10.3406/reg.1996.2678 . hal-02536195

\section{HAL Id: hal-02536195 \\ https://hal-normandie-univ.archives-ouvertes.fr/hal-02536195}

Submitted on 12 May 2020

HAL is a multi-disciplinary open access archive for the deposit and dissemination of scientific research documents, whether they are published or not. The documents may come from teaching and research institutions in France or abroad, or from public or private research centers.
L'archive ouverte pluridisciplinaire HAL, est destinée au dépôt et à la diffusion de documents scientifiques de niveau recherche, publiés ou non, émanant des établissements d'enseignement et de recherche français ou étrangers, des laboratoires publics ou privés. 


\title{
Sur un Topos romanesque oublié : les scènes de banquets
}

\section{Corinne Jouanno}

\section{Résumé}

Le topos du banquet fait partie des ingrédients obligés du roman grec. Étroitement lié au développement de l'intrigue amoureuse, il possède souvent une dimension métalittéraire et porte volontiers la marque de la seconde sophistique. La prolifération des scènes de banquet dans les romans byzantins du XIle siècle confirme le caractère topique de ce motif : on note toutefois quelques tendances nouvelles, goût pour les realia et dimension comique, imputables à l'influence des «festins» cyniques, et aussi place accrue faite à la réflexion morale.

\begin{abstract}
The symposium-topos is among the necessary items of the greek romances. In close connection with the development of the love story it often has a metaliterary meaning and it frequently bears the print of second sophistic. The increasing number of symposium scenes in byzantine romances of the twelfth century confirms the topical character of this motive : we can nevertheless note some new trends : taste for realia, comical dimension, both to be imputed to cynical deipnon influence, and also greater importance given to moral reflection.
\end{abstract}

\section{Citer ce document / Cite this document :}

Jouanno Corinne. Sur un Topos romanesque oublié : les scènes de banquets. In: Revue des Études Grecques, tome 109, Janvier-juin 1996. pp. 157-184;

doi : https://doi.org/10.3406/reg.1996.2678

https://www.persee.fr/doc/reg_0035-2039_1996_num_109_1_2678

Fichier pdf généré le 18/04/2018 


\section{Corinne JOLANNO \\ SUR UN TOPOS ROMANESQUE OUBLIÉ : LES SCÈNES DE BANQUETS}

RÉscyé. - Le topos du banquet fait partie des ingrédients obligés du roman grec. Etroitement lié au développement de l'intrigue amoureuse, il possède souvent une dimension métalittéraire et porte volontiers la marque de la seconde sophistique. La prolifération des scènes de banquet dans les romans byzantins du XIr siècle confirme le caractère topique de ce motif : on note toutefois quelques tendances nouvelles. goût pour les realia et dimension comique. imputables à l'influence des "festins" cyniques, et aussi place accrue faite à la réflexion morale.

Abstracr. - The symposium-lopos is among the necessary items of the greek romances. In close connection with the development of the love story it often has a metaliterary meaning and it frequently bears the print of second sophistic. The increasing number of symposium scenes in byzantine romances of the twelfth century confirms the topical character of this motive : we can nevertheless note some new trends : taste for realia, comical dimension, both to be imputed to cynical deipnon influence, and also greater importance given to moral reflection.

Dans le livre récemment consacré par F. Létoublon aux lieux communs du roman grec ${ }^{2}$, figurent au nombre des topoi recensés par l'auteur tempêtes et pirates, prisons et chaînes, mensonges et travestissements ... Mais nulle part il n'est fait mention de ces

(1) Fr. Létoublon, Les lieux communs du roman. Stéréotypes grecs d'aventure et d'amour. Leiden. ...Y., Köln, 1993.

REG tome 109 (1996/1), 157-184. 
scènes de banquets qui pourtant ponctuent régulièrement tous les romans grecs conservés. Le même silence se retrouve dans les autres études sur la littérature romanesque de l'époque impériale, où la fréquence et l'intérêt de ce type de séquences semblent avoir échappé à l'attention des spécialistes ${ }^{2}$.

Et pourtant, il n'est pas de roman grec sans banquets. Même le texte un peu schèmatique de Xénophon d'Éphèse en offre plusieurs exemples : banquet apprêté pour les noces de Périlaos et d'Anthia en III, 5,1 sq. ou banquet final célébrant les retrouvailles des héros en $V, 13,5$. C'est un motif qui, d'ailleurs, apparaît souvent par séries : ainsi trouve-t-on chez Longus deux banquets champêtres consécutifs, organisés pour fèter la libération de Chloé, qu'avaient enlevée les Méthymniens (II, 30, 5-37, 3), et le roman d'Achille Tatius évoque successivement trois banquets offerts par le père de Clitophon à l'arrivée de Leucippé et de sa mère (I, $5 ; I I, 3$ et 9 ). On note donc la récurrence du thème, mais aussi le soin apporté par les romanciers au traitement d'un sujet qui manifestement les intéresse, car ils n'hésitent pas à développer fort longuement certaines scènes de banquets : ainsi Héliodore évoque-t-il très en détail le festin offert par Théagène lors de son ambassade à Delphes (III, 10-11), et la composition spéculaire de son œuvre le conduit mème à dédoubler, à deux reprises, l'évocation d'une scène de banquet : ainsi le repas par lequel les pirates ravisseurs de Théagène et Chariclée célèbrent leur arrivée en Égypte est-il décrit deux fois, puisque à la narration au premier degré qui ouvre le roman (I, $1,4 \mathrm{sq}$.) fait écho le récit rétrospectif de Calasiris en $V, 28 \mathrm{sq}$. De manière analogue, l'évocation du banquet organisé par Nausiclès est fragmentée en deux séquences complémentaires ( $V$. 15,3 sq. et $33,4-34,1$ ).

Il faut bien avouer toutefois que les contours du "topos de banquet" souffrent d'un certain flou, qui tient peut-ètre pour une part à l'imprécision de la terminologie employée par les romanciers. En toute rigueur, en effet, on appelle symposium le moment du "banquet " qui fait suite au dîner et qui, les besoins alimentaires une fois satisfaits, est consacré à la boisson et aux divertissements. Mais les romanciers ne distinguent pas toujours

(2) Cf. l'absence de toute remarque sur la question dans l'article consacré par A. M. Scarcella à la présence de l'élément dionysiaque (mỵthe et rituel) chez. les romanciers grecs, "Morfologia e ideologia dionisiaca nel romanzo greco d'amore", Quaderni dell' Istituto di Filosofia di Perugia, 3, 1985, 11 -23. 
clairement ces deux séquences rituelles, et lorsque Achille

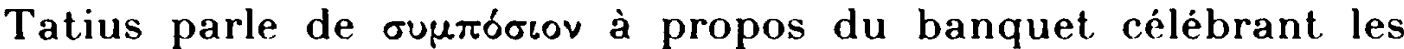
retrouvailles des héros en VIII, 4, 1, c'est à l'ensemble de la

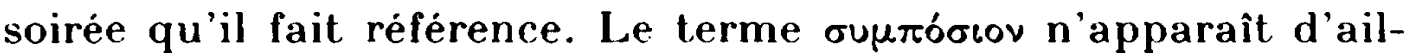
leurs pas toujours là où on l'attendrait : Achille Tatius ne l'emploie pas lorsqu'il évoque au début de son roman les trois festins donnés par le père de Clitophon, alors qu'il mentionne pourtant

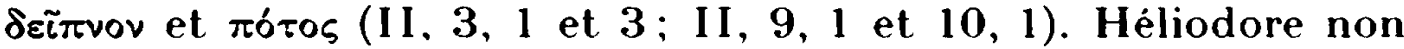

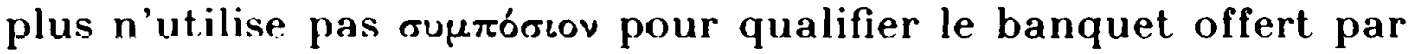
les commerçants phéniciens à l'occasion de la victoire gymnique de l'un des leurs : c'est à $\varepsilon \dot{\omega} \omega \chi i \alpha$ qu'il recourt pour désigner ce qui est pourtant, de toute évidence, un banquet en règle, avec son cortège de libations, de chants et de danses (IV, 16.3 et 6). On a d'ailleurs l'impression que dans le roman grec en général,

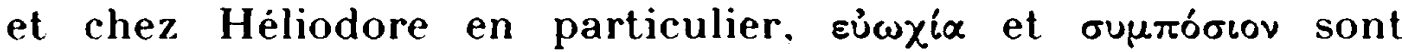
souvent employés l'un pour l'autre, sans nuance de sens particulière $^{3}$. Or le terme $\varepsilon \dot{\omega} \omega \chi^{i \alpha}$ possède une acception relativement large puisque, évoquant l'idée de bonne chère, il peut s'appliquer à tout repas plantureux, quelles qu'en soient les modalités et indépendamment même du nombre de convives présents.

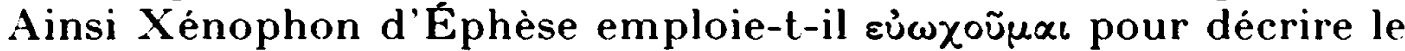
copieux repas pris en tète-à-tête par Habrocomès et le brigand Hippothoos (III, 1,4). Et c'est peut-être parce que le sens

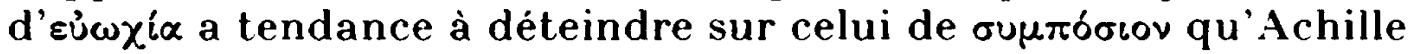
Tatius recourt à ce terme, devenu quasiment synonyme de "partie fine", pour qualifier le premier dîner partagé à Éphèse par Clitophon et Mélitté, alors que ceux-ci sont, à ce qu'il semble,

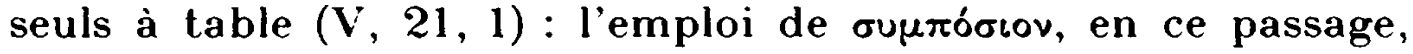
paraît donc motivé uniquement par la qualité du repas, et peutêtre aussi par le fait que, censé préluder à la consommation du mariage des deux personnages, jusque-là resté blanc, ce dîner réitère symboliquement leur festin de noces.

Pareilles imprécisions terminologiques ne sont pas sans conséquences. Elles contribuent au statut ambigu d'un certain nombre de scènes de repas qui, sans posséder peut-être toutes les caractéristiques des symposia, leur sont pourtant étroitement apparentées, et que, pour cette raison, nous avons choisi d'étu-

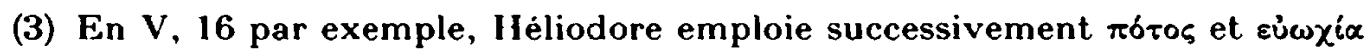

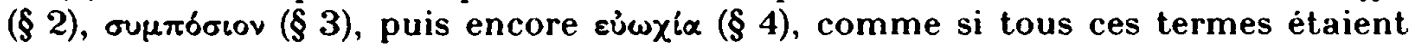
parfaitement synonymes. 
dier conjointement, à titre de variantes du même lopos. Tel le dîner pris par Habrocomès avec les brigands d'Hippothoos, dîner dont rien ne dit qu'il n'est pas conforme à leur ordinaire, mais qui présente pourtant les deux temps caractéristiques du banquet - consommation alimentaire et "beuverie" - et qui, dans l'histoire du héros, va marquer une étape importante, puisque c'est à cette occasion qu'Habrocomès apprend la (fausse) mort d'Anthia (Ephes., III, 9, 2 sq.). Tels aussi les trois repas consécutifs pris par Daphnis chez les parents de Chloé, lors de la visite hivernale qu'il rend à la jeune fille (Pastorales, III, 7-11): qualifiés par l'éditeur du roman de "petite fète de famille", ils n'en sont pas moins classés par lui au nombre des scènes de banquets ${ }^{4}$. Enfin, le repas au cours duquel Calasiris raconte à Cnémon les aventures de Théagène et Chariclée, et qui donc sert de cadre à un récit s'étendant sur plus de deux livres (Ethiop., II, 24, 5-V, 1, 2) fait également figure de quasi-banquet, même si les convives ne sont que deux et partagent une collation très frugale.

Le caractère récurrent de ces scènes de banquets ou quasibanquets dans des ouvres ayant l'amour pour sujet principal n'est, à vrai dire, guère surprenant, quand on songe au lien étroit unissant symposium et érotisme depuis les temps les plus reculés. C'est dans le cadre des banquets qu'a pris naissance la

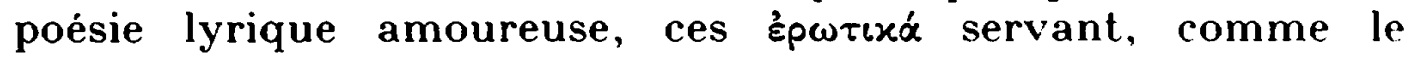
remarque F. Lasserre ${ }^{5}$, d'assaisonnement aux plaisirs du symposium. E. L. Bowie, qui s'est attaché à répertorier les sujets topiques de la conversation symposiaque à l'époque archaĩque et classique ${ }^{6}$, note le rôle tout aussi important joué par le motif

(4) J.-R. Viellefond, CUF, Introduction, p. 62.

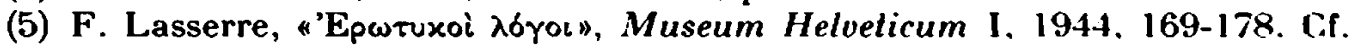
Euripide Rhésos, 360-367 : "L'antique Ilion-va-t-elle revoir ces jours de beuverie, de danse et de liesse, parmi les chants d'amour et la lutte joyeuse des larges coupes échangées? tandis que sur mer les Atrides vers Sparte s'en retourneront. tournant le dos à nos rivages?" (trad. M. Delcourt-Curvers, Pléiade). Beaucoup de poèmes d'Anacréon témoignent de cette étroite association de l'amour el du banquet : cf. éd. B. Gentili, Rome, 1958 , nos 38,65 , etc. Le poème 56 est mème une véritable "défense et illustration" de la poésie symposiaque érotique : $\mathrm{O} \circlearrowright$

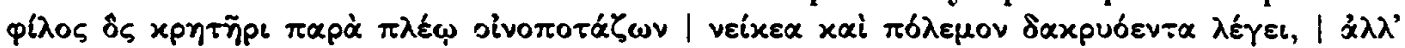

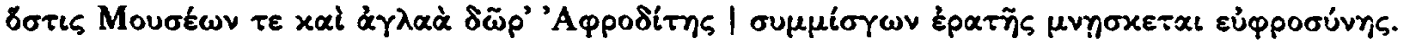

(6) E. L. Bowie, "Greek Table-Talk before Plato", Rhétoriques de la conuersation de l'Antiquité à l'époque moderne, éd. L. Pernot. Rhetorica. A Journal of Rhetoric, 11, no 4, 1993, p. 355-373. 
érotique dans les échanges verbaux - que ce soit sous la forme de "confidences" galantes ou de commérages à propos des amours d'autrui - et une remarque incidente de Longus confirme le tour volontiers grivois pris par les conversations de banquets : le romancier dit en effet du parasite Gnathon que "dans les banquets de débauchés, il avait appris toutes les histoires d'amour"(IV, 17, 3). Les jeux mêmes pratiqués dans le cadre du banquet possèdent souvent une dimension érotique ; témoin le cottabe, cet exercice d'adresse où les coups, dédiés à l'être aimé, sont censés, en cas de victoire, ètre le signe d'un amour garanti. Et il n'est pas jusqu'aux instruments du banquet qui ne portent la marque d'Éros, puisque les scènes légères sont fréquentes sur les coupes dont usent les convives?.

Ce lien étroit unissant érotisme et banquet explique que le symposium ait pu apparaître aux philosophes comme le lieu rèvé d'une réflexion sur l'amour et que Platon ou Xénophon aient choisi de montrer Socrate au banquet, lorsqu'ils voulurent le faire parler de la nature et des pouvoirs d'Éros ${ }^{8}$.

Or il est un roman grec qui reprend à son compte, très directement, l'héritage des banquets philosophiques : il s'agit de l'histoire de Métiochos et Parthénopé ${ }^{9}$, où un symposium à la mode platonicienne est inséré dans la trame narrative et exploité à des fins romanesques - pour autant qu'on en puisse juger à partir du bref fragment qui nous reste de ce texte. Le passage qui nous en a été conservé met en effet en scène un banquet, donné par Polycrate, tyran de Samos, en l'honneur de son hòte Métiochos. Parmi les participants du banquet figurent la fille de Polycrate,

(7) Cf. Fr. Lissarague, C'n flot d'images. Une esthètique du banquet grec, Paris, 1987. Sur le cottabe, voir le développement intitulé "Vin damour", p. 75-82. Lissarague évoque au cours de son étude bon nombre de pièces de vaisselle

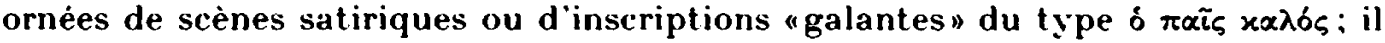
mentionne mème l'existence de quelques vases en forme de sexe qui, dit-il, "impliquent le buveur dans un jeu érotique manifeste" (p. 56).

(8) On retrouve aussi en filigrane, dans les banquets philosophiques, la présence de l'intrigue amoureuse, à travers les couples Callias-Autolycos ou Antisthène-Socrate chez Xénophon, Pausanias-Agathon ou Alcibiade-Socrate chez. Platon.

(9) M. Maehler, "Der Metiochos-Parthenope Roman ", Zeitschrift für Papyrologie und Epigraphik 23, 1976, 1-20. Pour l'influence du Banquet platonicien sur le roman antique et son rôle de "répertoire de thèmes", cf. Gr. Anderson, Eros Sophistes. Ancient Novelists at Play, Chico, 1982, passim, et notamment p. 5, 23-32 (Achille Tatius ou l'amour platonique travesti), 55 (Métiochos), 71 (Pètrone), 82 sq. (Apulée). 
Parthénopé, et le philosophe Anaximène. Un débat, proposé,

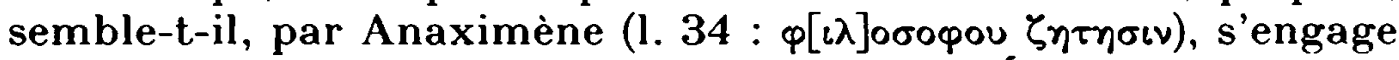
entre les convives à propos de la nature d'Éros, et cette discussion sur l'amour donne lieu à un affrontement entre Métiochos et Parthénopé qui, vraisemblablement, se sont rencontrés et épris l'un de l'autre peu de temps avant le banquet. Comme Métiochos vient de critiquer les représentations traditionnelles d'Éros, tout en prétendant n'avoir pour sa part aucune expérience de l'amour et même souhaiter ne l'éprouver jamais (1. 3962), Parthénopé, blessée de ce qui lui apparaît comme un reniement, s'oppose vivement aux propos du jeune homme : $x \alpha$ -

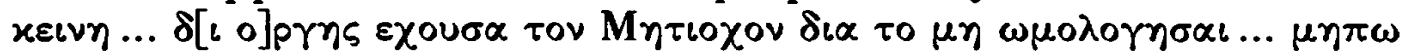

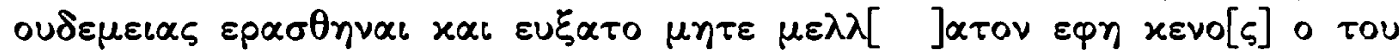
$\xi_{\varepsilon v o u} \lambda$ npos (1. 65-69). Ainsi la discussion théorique sur la nature du dieu se double-t-elle d'une querelle d'amoureux, et l'entretien philosophique devient-il prétexte à peindre la réaction des deux héros sous l'emprise de l'amour naissant.

Pareil lien entre scène de banquet et intrigue amoureuse se retrouve souvent dans les romans dont nous possédons l'intégralité. Il est particulièrement marqué au début de Leucippé et Clitophon - la scène de première rencontre étant suivie d'une série de trois repas qui offrent au héros l'occasion de retrouver Leucippé et le font s'enflammer encore davantage à sa vue. Ainsi les trois banquets, prétexte à variations sur le thème du regard ${ }^{10}$, sont-ils mis au service de l'histoire d'amour. Le symposium devient en effet pour les amoureux un lieu d'échange de signes, comme en témoigne aussi le jeu érotique, bien connu, de la coupe partagée, dont la description vient clore la troisième séquence de repas. Achille Tatius y souligne clairement la valeur métonymique de ce geste, en concluant : "... nous bùmes ainsi

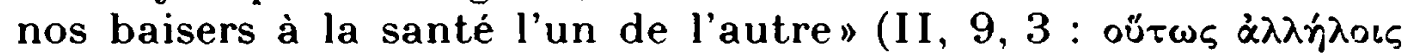

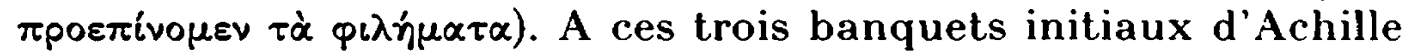
Tatius, on peut comparer les trois repas offerts à Daphnis par les

(10) Cf. le motif de la "consommation oculaire», à la fin du premier banquet : "Alors, les autres s'en allèrent, après avoir mesuré leur plaisir à leur ventre. mais

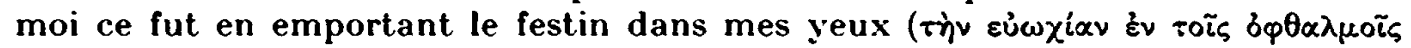

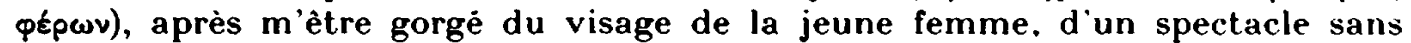

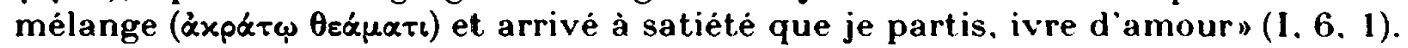
On retrouve le même motif dans la description du premier repas partagé par Clitophon et Mélitté, en $V, 13,3$ et 5 : Mèlitté est en effet dépeinte comme trop absorbée par la contemplation de Clitophon pour pouvoir se préoccuper de manger. 
parents de Chloé, lorsque le jeune chevrier vient leur rendre visite au plein cœur de l'hiver : ils ont même fonction galante, et l'on y retrouve d'ailleurs, quoique plus discrètement évoqué, le jeu furtif de l'échange des coupes (III, 8, 2) ${ }^{11}$.

Chez Chariton et Héliodore aussi se rencontrent des banquets qui sont le lieu de l'obsession amoureuse. Le motif prend toutefois chez eux une résonance nouvelle, du simple fait que la femme aimée ne participe plus au repas, comme c'était le cas chez Achille Tatius ou Longus ${ }^{12}$. Evoquant le banquet qui suit immédiatement la première rencontre de Dionysios et de Callirhoé (II, 4, 1-2), Chariton dépeint son personnage silencieux et tout entier absorbé par la pensée de la jeune femme. On retrouve exactement la même situation chez Héliodore, mais traitée

(11) Cf. aussi Iléliodore VII, 27, 3: Arsacé, qui veut séduire Thèagène, prétend jouer avec lui au jeu de la coupe : "Au lieu d'épuiser la coupe. elle y laissa exprès quelques gouttes, comme pour les offrir à Théagène". Sur le banquet comme terrain de séduction privilègié. cf. les remarques d Ovide au livre I de l'Arl d'aimer : non seulement le poète mentionne les festins au nombre des occasions de rencontres galantes ( $v$. 229 sq.), mais il souligne aussi combien la proximité conviviale facilite les mancxuvres dapproche ( $\forall .567$ sq.), et recommande. entre autres tactiques, celle de la coupe partagée : "Tàche de t'emparer le premier de la coupe qu'auront touchée ses lèvres charmantes. et du còté où elle aura bu, bois aussi” ( $v .573-574)$.

(12) Pareille différence de traitement peut s'expliquer par le caractère plus familial des banquets mis en scène par Achille Tatius ou Longus. Les symposia évoqués dans les romans de Chariton (II, 4, I-3; IV, 3,7-12; IV. 5, 7-10) et d'Iléliodore (III, 10-11,4: IV, 16.3-17,1) ont au contraire une dimension publique qui justifie l'exclusion de toute présence féminine. Car le banquet était à l'origine une assemblée masculine, où les femmes (esclaves, danseuses ou flùtistes) jouaient le simple ròle d'accessoire. Aussi la participation d'une femme aux symposia passait-elle à l'époque classique pour une marque d inconduite (cf. Isée, Succession de Pyrrhus, 14 : "On ne voit pas une femme légitime accompagner son mari au banquet ni festoyer avec des étrangers. surtout avec les premiers venus"). Si à partir de l'èpoque hellénistique, à la faveur d’un tout relatif mouvement d'èmancipation féminine, les usages se sont sans doute quelque peu assouplis, et si l'on voit des reines comme Arsinoé Philadelphe assister aux symposia (cf. Cl. Vatin, Recherches sur le mariage el la condition de la femme mariée à l'époque hellénistique, Paris, 1970, p. 80), la promiscuité conviviale n'en persiste pas moins à ètre perçue comme dangereuse pour la vertu des femmes. Aussi est-il d'usage que lors des banquets de noces, où hommes et femmes participent ègalement à la fête, des lieux séparés soient réservès à chacun des deux sexes (cf. Cl. Vatin, op. cit., p. 210 sq.). Dans le roman d'Héliodore, on voit ce principe de distribution de l'espace mis en application par Chariclès en V, 15, 3 : "Ensuite eut lieu le banquet, auquel il invita tous les assistants. [...] Il fit manger les femmes à part dans l'enceinte du temple, et les hommes dans le parvis." 
avec plus d'ampleur: Théagène, en effet, offre un banquet le premier soir de son ambassade sacrée à Delphes, alors même qu'il vient de rencontrer Chariclée, dont la vue l'a totalement bouleversé. Calasiris, qui raconte la scène, souligne les bizarreries de comportement du jeune Thessalien tout au long de la soirée - bizarreries bien évidemment à mettre au compte de ses toutes nouvelles préoccupations amoureuses : "Théagène mon-

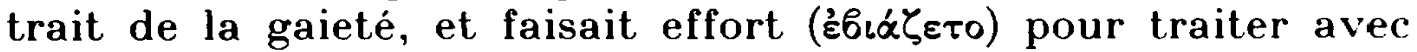
bonne humeur les convives. Mais je voyais bien où allaient ses pensées. Tantôt ses yeux roulaient dans sa tête, tantôt poussant un soupir profond sans raison apparente, l'œil morne et la tète baissée, il paraissait abîmé dans ses réflexions. Puis soudain, il se

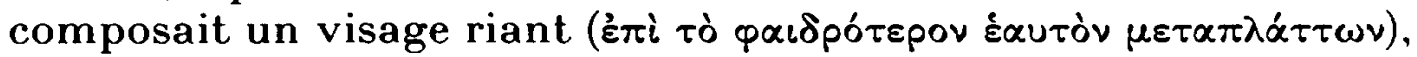
comme s'il reprenait conscience et se rappelait lui-mème à la réalité, passant ainsi facilement par tous les états" (III, 10,4). En insistant de cette façon sur les efforts de son personnage pour cacher son émoi à ses hôtes, Héliodore cesse évidemment de faire apparaître le banquet comme un espace favorable aux amours; jouant de la dialectique privé/public et associant le symposium à l'idée de contrainte de soi, il le transforme en lieu de souffrance pour l'amoureux en proie à la monomanie.

De fait, Héliodore voit souvent dans les scènes de banquets l'occasion d'évoquer la solitude pathétique de l'individu exclu par son chagrin des festivités collectives et rencogné dans sa douleur par l'insouciance des autres. Ainsi montre-t-il Chariclée priant, à l'écart pour le salut de Théagène, tandis que le marchand Nausiclès et ses invités, "rassasiés de bonne chère", chantent et dansent $(\mathrm{V}, 15,3)$; et lorsqu'un peu plus tard, le même Chariclès célèbre dans la liesse les noces de sa fille avec Cnémon, Chariclée à nouveau se retire, seule dans sa chambre, pour se livrer au désespoir d'avoir perdu son bien-aimé (VI, $8,3)^{13}$. Les situations analogues ne manquent pas dans les autres romans ${ }^{14}$, mais c'est Xénophon d'Éphèse qui applique à

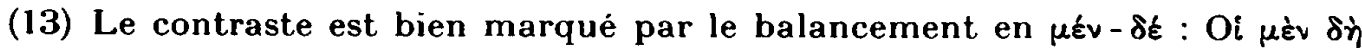

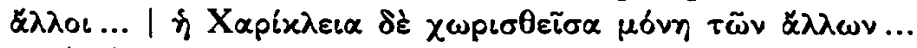

(14) Cf. Chariton évoquant en VI, 2, 4-5 les sacrifices décrétés par le Grand Roi pour retarder le procès de Callirhoé : "On entendait résonner la flúte et roucouler le chalumeau, accompagnant les mélodies des chanteurs: les porches des maisons étaient enfumés de parfums; toutes les ruelles formaient le cadre

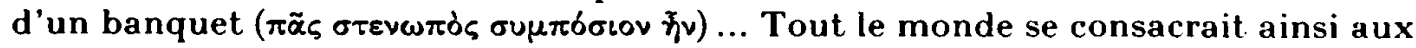
réjouissances; seuls trois personnages étaient accablés d'affliction : Callirhoé. 
ce thème le traitement le plus extrème, lorsqu'il met en scène le banquet de noces de Périlaos et d'Anthia - noces forcées que l'héroïne n'a acceptées que sous la contrainte : en effet, tandis que son futur époux est à table et festoie avec ses amis, Anthia, retirée déjà dans la chambre nuptiale, absorbe le poison qui doit lui éviter de "trahir la foi jurée à Habrocomès" (I I I, 6, 4-5).

Le motif $\mathrm{du}$ banquet-source de larmes plonge évidemment ses racines au cœur même de la littérature homérique : on songe aux pleurs versés par Ulysse lors des festins chez Alcinoos (Odyssée, VIII, $83 \mathrm{sq}$. et $521 \mathrm{sq}$.). Et dans le roman grec comme chez Homère, c'est parfois le chagrin inopinément manifesté par un personnage qui suscite les questions des autres et donne lieu aux confidences : ainsi le brigand Hippothoos est-il amené à raconter. sa tragique histoire à Habrocomès pour avoir. au beau milieu d'un repas, versé des larmes inattendues qui ont attisé la curiosité de son commensal (III, 1,4). Certes, il est difficile de parler ici de scène de banquet car, si le repas est copieux

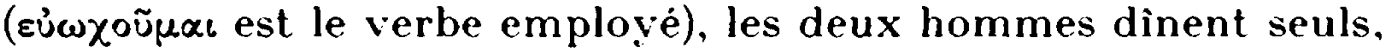
mais il semble, à parcourir les romans grecs, que la prégnance du modèle odysséen soit telle que le repas fasse figure de cadre obligé du récit-confession - qu'il s'agisse de véritable symposium ou de variantes plus modestes : ariston improvisé comme chez Achille Tatius, sur le bateau qui emmène les héros en Egypte (II, $33 \mathrm{sq}$.), ou collation en tète-à-tète comme chez Héliodore : car le léger repas au cours duquel Calasiris raconte à un Cnémon insatiable de récits la première partic des aventures de Théagène et Chariclée est bel et bien traité comme un banquet, avec son cortège de libations, ses réflexions sur les exigences du ventre et les effets du vin (II, 22, 2 sq.), et il joue dans l'économie du roman exactement la même fonction que le véritable symposium à l'occasion duquel Calasiris termine son récit devant un auditoire élargi, pour qui il se contente de résumer rapidement ce qu'il a déjà raconté à Cnémon dans le plus grand détail $(\mathrm{V}, 15,3 \mathrm{sq}$.$) . Or dans ces deux passages, la référence$ homérique est évidente : les deux récits successifs de Calasiris forment à l'intérieur du roman une monumentale analepse (II, $24,5-\mathrm{V}, 1,2$ et $\mathrm{V}, 17-33,3)$ comparable à celle constituée dans l'Odyssée par les récits chez Alcinoos, et Héliodore prend même

Dionysios et surtout Chairéas" : cf. aussi Achille Tatius III, 16, 1 (où le motif cst tout juste esquissé). 
soin de rendre ouvertement hommage à son modèle en plaçant à l'orée de son premier "pseudo-banquet" une référence au texte fondateur, en liaison avec le thème $d u$ repas, puisque Calasiris loue Homère d'avoir appelé le ventre un "damné tyran" (זйv

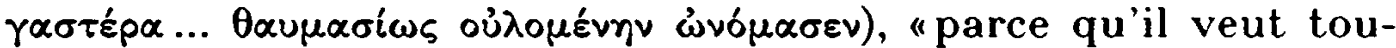
jours être le premier servi" (I I, 22, 5) ${ }^{15}$.

Au nombre des symposia générateurs de récits d'aventures figurent évidemment dans les romans grecs les inévitables banquets de retrouvailles. Si Xénophon d'Éphèse, évoquant le festin magnifique organisé pour fêter la réunion d'Habrocomès et d'Anthia, se contente de dire : "Ce fut une longue suite de récits où chacun racontait ce qu'il avait fait et subi " $(\mathrm{V}, 13,5)$, Achille Tatius, moins discret, détaille le contenu des récits de ses protagonistes. Evoquant au livre VIII les deux banquets successivement offerts par le prêtre d'Éphèse à Clitophon, Leucippé et son père, qui viennent de se retrouver et qu'il a pris sous sa protection, l'auteur insère dans la première scène de symposium le récit de Clitophon (VIII, 5), qui pour les lecteurs fait fonction de récapitulation, puisque les aventures racontées par le héros sont précisément celles qui constituent le corps du roman. En revanche, le récit de Leucippé et celui de Sostratos, insérés dans la seconde scène de symposium (VIII, 16 et 17-18), viennent combler des lacunes de la narration primaire - lacunes consécutives à l'adoption du point de vue interne : car au début du livre VIII, le lecteur partage l'ignorance du héros-narrateur touchant toute une partie des aventures de Leucippé, et il ne sait pas plus que Clitophon ce qu'il est advenu de sa sour Calligone, enlevée au livre $I$. Les récits de l'héroïne et de son père ont donc pour fonction de répondre à ces questions laissées en suspens, et le banquet de retrouvailles s'avère ainsi jouer un ròle essentiel dans l'économie du roman.

Les symposia romanesques apparaissent aussi, fréquemment, comme un lieu d'échange d'anecdotes et de récits mythologiques. Témoin le banquet champêtre célébrant dans Daphnis et Chloé la libération de l'héroïne enlevée par les Méthymniens : on y voit les vieux bergers raconter des histoires de jeunesse, se vanter de leurs exploits passés, ou puiser dans le riche répertoire des amours des dieux pour divertir la compagnie (II, 32, 3 sq.).

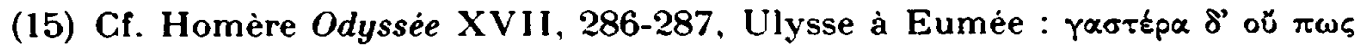

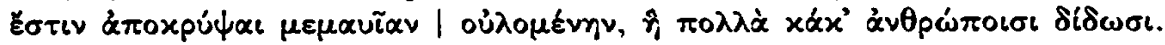


Ainsi Lamon évoque-t-il la légende de Syrinx, mimée ensuite par Daphnis et Chloé (I I, 34 et 37). La même histoire de métamorphose figure également chez Achille Tatius, lors du premier banquet de retrouvailles, sous forme de mythe étiologique, puisque le prêtre d'Artémis raconte cette légende pour expliquer l'origine du test de virginité auquel Leucippé doit être soumise (VIII, 6, 7-14). Le symposium, avec ses échanges de récits, représente donc pour les romanciers une possibilité d'accentuer encore le caractère polyphonique de leurs œuvres. L'insertion de récits mythologiques à l'intérieur de la trame narrative peut d'ailleurs servir de contrepoint à l'histoire vécue par les héros. Telle est bien la fonction du mythe d'Apollon et Daphné, tel qu'il apparaît dans la première scène de banquet du roman d'Achille Tatius $(1,5,5)$ : Clitophon vient en effet de rencontrer Leucippé et, bouleversé par cet amour tout neuf, il s'embrase encore davantage en entendant chanter, au cours du symposium donné en l'honneur de la jeune fille et de sa mère. l'histoire des amours d'Apollon : "Car les histoires d'amour attisent le désir. Et même si l'on s'exhorte à la sagesse, l'exemple vous incite à l'imitation, surtout lorsque cet exemple vient de quelqu'un qui vous est supérieur" (I, 5, 6; trad. modifiée). Prenant le dieu pour modèle, Clitophon s'encourage donc à mener avec hardiesse la conquête de Leucippé, faisant ainsi jouer à la mythologie le rôle assez suspect de caution d'immoralité ${ }^{16}$.

La façon dont s'ébauche, à l'intérieur de cette scène de banquet, une réflexion sérieuse sur les pouvoirs et la fonction du mythe prouve que les symposia mis en scène par les romanciers ne sont pas toujours dènués d'ambitions intellectuelles. Achille Tatius et surtout Héliodore confèrent volontiers à leurs banquets une dimension réflexive qui leur donne valeur d'arts poétiques. Ils profitent en effet de la situation d'échange verbal ainsi représentée pour formuler des remarques d'ordre métadiégétique qui, si elles concernent les histoires racontées au banquet, valent aussi pour le récit romanesque lui-même. Tel le commentaire prononcé par le prêtre d'Artémis pour encourager Clitophon à narrer ses aventures : "Elles me semblent en effet

(16) Sur le lien fréquent de la mythologie et de la transgression dans l'univers d'Achille Tatius, cf. les remarques de Fr. Létoublon, op. cit., p. 161-164: la mythologie semble être devenue pour le romancier "un répertoire de prétextes pour enfreindre ce que l'on sait être la norme éthique". 
comporter des tours et des détours ( $\left.\pi \varepsilon p \iota \pi \lambda \circ x_{\alpha} \varsigma_{\varsigma} \tau \iota v \alpha \varsigma\right)$ qui ne sont pas sans agrément" (VIII, 4,2) - justification a posteriori des multiples rebondissements qui forment la trame du roman luimême et lui donnent un caractère si rocambolesque. Il est souvent question, chez Achille Tatius comme chez Héliodore, du plaisir que donnent les récits : «... si tu nous versais le récit que nous désirons entendre, ce serait nous régaler du plus délicieux des breuvages", déclare Nausiclès à Calasiris (Ethiop., V, 16, 1), et Cnémon, dépeint à diverses reprises par Héliodore comme un

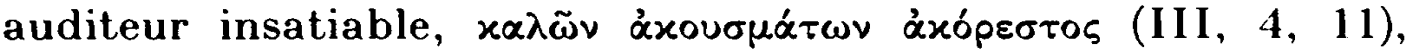
surenchérit en disant attendre du récit de Calasiris "un divin plaisir" $(\mathrm{V}, 16,3)^{17}$ : or ce "divin plaisir", c'est aussi le but ultime à quoi tend le romancier, soucieux de captiver son public.

La dimension réflexive ainsi prêtée à leurs scènes de banquets par les deux plus sophistiqués des romanciers grecs n'est toutefois pas pure invention de leur part : c'est, dans une certaine mesure, un trait hérité de la tradition symposiaque. Car, comme le remarque Fr. Lissarague, la poésie de banquet se plaît à sa propre représentation, elle aime les jeux de miroirs et parle volontiers des plaisirs du chant, qu'elle associe à ceux de la table en un faisceau de métaphores où le vin devient symbole de poésie $^{18}$. Or on retrouve souvent l'association des plaisirs du vin et des joies du récit dans les scènes de banquets romanesques. Ainsi Héliodore fait-il dire à Cnémon : "Tu me parais entrer admirablement dans l'esprit de la divinité, toi qui fais marcher de pair Hermès et Dionysos, et fais couler des flots de paroles délicieuses avec des flots de vin" $(\mathrm{V}, 16,4: \ldots \lambda \delta \gamma \omega \nu \eta \eta \delta \nu \sigma \mu \alpha \tau \tilde{\varphi}$

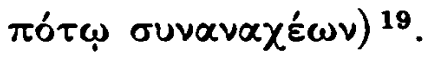

(17) Cf. A.T. VIII, 4, 2;4, 4; 15, 3 .

(18) Fr. Lissarague, op. cil., p. 83-84. Cf. l'invite finale de la neuvième Néméenne de Pindare, v. 114 sq. : "La tranquillité et le festin se plaisent ensemble; la victoire est rajeunie par les doux chants; et la voix s'enhardit auprès du cratère. Emplissez-le donc, ce doux prophète de l'hymne joyeux et distribuez le fils violent de la vigne ...". On retrouve le même rapprochement du vin et du chant au début de la sixième Isthmiqùe, sous forme d'image : "Comme lorsque entre convives fleurit la joie du banquet, mélangeons un second cratère

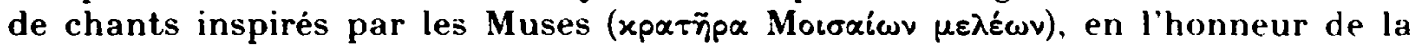
race de Lampon ...." (v. 1-4).

(19) Cf. II, 23, 5 : «Dionysos, tu le sais, se plaît aux contes et aime les comédies. Il vient de descendre en moi, et $m$ 'inspire le désir d'entendre une his-

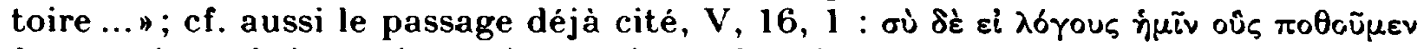

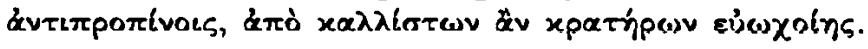


A la faveur de ce rapprochement entre vin et récit se surajoute à la discussion métalittéraire du banquet romanesque une dimension que l'on peut qualifier, en paraphrasant Fr. Lissarague, de "métasymposiaque" - dimension souvent présente dans la littérature et l'imagerie de banquet, qui témoignent du même goût pour la mise en abyme : de nombreux chants de banquet sont en effet consacrés à la célébration du symposium, et le décor des vases renvoie volontiers aux buveurs leur propre image ${ }^{20}$. Les banquets philosophiques eux-mêmes font une place considérable à la réflexion métasymposiaque, puisqu'ils s'interrogent sur ce que doit être le bon usage du banquet. Ainsi trouve-t-on chez Xénophon, comme chez Platon et chez Plutarque, de fréquentes remarques touchant la consommation $\mathrm{du}$ vin ou le type de plaisirs que doivent rechercher les convives ${ }^{21}$. Or ces deux questions sont assez fréquemment abordées dans les scènes de banquets romanesques. Les maximes ne manquent pas, évoquant les effets du vin : Achille Tatius en souligne la

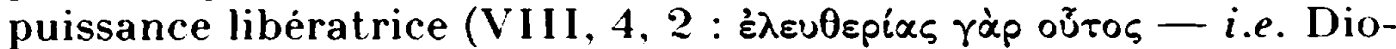
nysos - $\pi \alpha \tau \dot{r} p)$, Héliodore fait remarquer qu'il exacerbe la sensibilité : "On sait que le vin porte aux larmes" $(1,33,4)$. Mais c'est surtout sur les rapports étroits unissant le vin et l'amour que les romanciers se plaisent à insister: "F́ros et Dionysos,

(20) Cf. Lissarague, op. cil.. p. 83-103. "Réflexions": L. Rossi. "Il simposio greco arcaico e classico come spect acolo a se stesso". Speltacoli conviviali dall' antichita classica alle corti italiane dell 400. Viterbo, 1983, 41-50. Le poème 346 LP d'Alcée. souvent cité. est un bon exemple de la réflexivité chère à la Muse symposiaque : "Buvons: à quoi bon attendre les lampes: le jour n’a plus qu'un doigt de longueur: apporte de grandes coupes. mon amour. des coupes bien ornées : le vin. pour l'oubli. par le fils de Sémélé et de Zeus. a été donné aux hommes; remplis-les, jusquau bord, d'une partie de vin pour deux parties d'eau, et qu'une coupe chasse l'autre (=CLF n'113). Cf. aussi $338 \mathrm{LP}=$ CUF 62. Théognis, Poèmes élégiaques, I, 873-876; 879-884; 1046-1047 ...

(21) Cf. notamment Xénophon. Banquet: II, 24-26 (usage du vin); IV, 8 (critique des raffinements de table) : III, 2 et VII. 2-5 (divertissements). Platon. Banquet : 176 a-d et 213 e-214 a (usage du vin): $176 \mathrm{e}$ (divertissements : musique et conversation). Plutarque, Banquet des Sept Sages : chap. 4 (pouvoir du vin et plaisirs de la table) et 13 (du bon usage de la boisson ; comparaison $\lambda \sigma_{\gamma} \circ \varsigma_{\text {- olvos en }}$ $156 \mathrm{~d}$ ) ; Propos de table : passim, et notamment II, 1 (sujets de conversation agréables); II I, 5 et-7-9 (effets du vin) ... Comme le remarque Lissarague. op. cit.. p. 7, "parlant du vin, les Grecs sont intarissables". Ainsi trouve-t-on également dans les Lois de Platon une réflexion approfondie du philosophe sur la valeur éducative des symposia et les vertus de la boisson comme instrument de mise à l'èpreuve de la personnalité (637 b-674 a). C. P. Boyancé, "Platon et le vin", $B A C B 10,1951,3-19$. 
deux puissants dieux, dit Achille Tatius, un fois qu'ils se sont emparés d'une âme, la rendent folle jusqu'à l'impudence, l'un en la brûlant de son feu habituel, l'autre en apportant le vin comme stimulant, car le vin est un aliment de l'amour" (II, $3,3)$. Héliodore rapproche pareillement l'état de l'homme ivre et celui de l'amoureux : "Car la pensée d'un amoureux, comme celle d'un homme ivre, est mobile et inconstante; leur âme à l'un comme à l'autre nage dans les flots de leur humide passion. Voilà pourquoi l'amoureux est porté à boire, et l'homme ivre à aimer» (III, 10,5).

Sur la question de la nourriture, les romanciers sont moins prolixes. Il est rare qu'ils évoquent les mets consommés par leurs héros, se limitant généralement à des formulations hyperboliques, mais imprécises pour suggérer la qualité du repas : Achille Tatius parle, en II, 3, 1, de préparatifs "particulière-

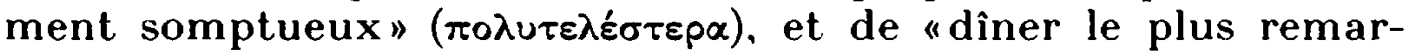

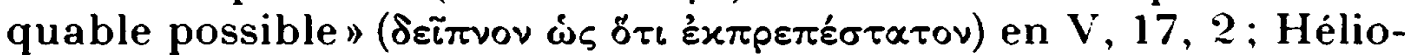
dore se contente pareillement de mentionner, en III, 10,3, la

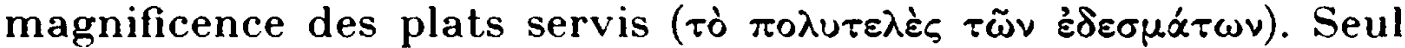
Longus est moins avare de détails concrets, sans doute parce qu'il prend prétexte des scènes de banquets pour souligner le contraste ville/campagne qui constitue l'un des axes de son œuvre : aux grillades préparées par ses héros, avec une simplicité toute homérique, pour leurs repas rustiques (cf. II, 31, 1) il

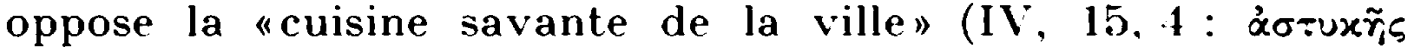

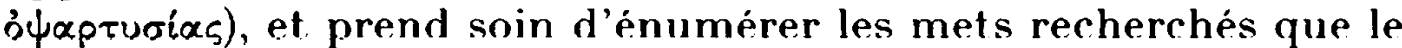
citadin Dionysophanès fait apprêter pour fêter son fils retrouvé $(I V, 26,1)^{22}$ : "On avait préparé beaucoup de vin, beaucoup de farine, oiseaux de marais, cochons de lait, toutes sortes de friandises au miel" - précisions qui ne vont pas sans une évidente distance critique, car Longus se moque volontiers des goûts raffinés des gens de la ville, comme il apparait clairement dans l'évocation du banquet de noces de Daphnis et Chloé, organisé "à la mode rustique et campagnarde", égayé de chants de moisson, d'airs de syrinx et de danses villageoises, et partagé par les chèvres elles-mêmes qui "vinrent paître à proximité», voisinage

(22) Le banquet organisé par le mème Dionysophanès pour tenter de retrouver le père de Chloé tèmoigne d'une recherche analogue, quoique Longus demeure plus flou et se contente de dire que le riche citadin fit "préparer un magnifique repas avec tous les meilleurs produits de la terre, de la mer. des lacs et des rivières" $(\mathrm{IV}, 34,2)$. 
qui, remarque incidemment l'auteur, ne plaisait guère aux citadins (I V, 38, 3-4).

Si le parti pris bucolique explique les réticences de Longus face aux délicatesses des gens de la ville, il faut toutefois noter que la méfiance à l'égard des raffinements gastronomiques est une constante chez les Grecs, et que les excès de table sont volontiers donnés pour une marque de barbarie. Ainsi n'est-ce peut-être pas sans arrière-pensée qu'Héliodore évoque les mets "d'une recherche et d'une délicatesse incomparables" servis à la table de la Perse Arsacé (VII, 18, 1), et quand il décrit le festin célébré par les pirates ravisseurs de Théagène et Chariclée, il place sans ambiguïté possible l'ensemble de la scène sous le signe de la démesure et de l'intempérance, parlant de "festin déréglé"

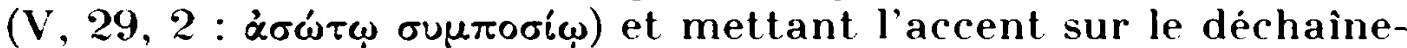
ment des barbares, qu'il décrit "avinés et prêts aux actes de violence", "sous l'emprise de l'ivresse et de la fureur" ( $I, 31,1$ et 32,1$)$. Ainsi le symposium peut-il jouer le rôle d'opérateur de différence entre Grecs et Barbares, entre bons et méchants, les uns sachant garder la mesure dans l'usage des plaisirs, tandis que les autres perdent tout contrôle sur eux-mèmes et laissent le banquet dégénérer en orgie ${ }^{23}$.

Chez Héliodore - et chez lui seul, sans doute parce qu'il est le plus philosophe des romanciers grecs - les pratiques symposiaques servent aussi à tracer une ligne de partage entre les sages et les gens du commun. En effet, les convives ordinaires se plaisent aux chants et aux danses et se satisfont de ces divertissements faciles qui sont l'attraction habituelle des banquets. Calasiris, évoquant le festin offert à Delphes par Théagène, mentionne la présence de danseuses et de flûtistes engagées par le jeune homme pour distraire ses hôtes, mais il évacue en une phrase la description de ces distractions qui, pour lui, n'offrent

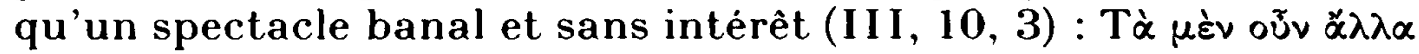

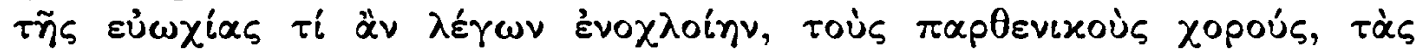
$\alpha u ̉ \lambda \eta \tau p i \delta \alpha \varsigma \ldots$ De mème, lorsqu'il est invité au banquet des commerçants phéniciens, il se retire sitôt réglée la question qui l'intéresse (la mise au point de la fuite de Théagène et Chariclée), absolument indifférent aux divertissements qui monopolisent

(23) Les "méchants" et les barbares sont souvent représentés affligès d'usages alimentaires déviants. Cf. A.T. III, 15 : repas cannibalique des bouviers égyptiens; V, 3, 7 et 5, 6-8 : "repas d'Érinyes" du Thrace Térée. 
l'attention des autres convives : "Quand je les quittai, dit-il, ils en étaient encore à la musique et aux danses. C'était une danse assyrienne, accompagnée par les flûtes qui jouaient un air de vive cadence. Tantôt ils sautaient en l'air avec légèreté, tantôt, accroupis près du sol, ils tournaient sur eux-mêmes comme des

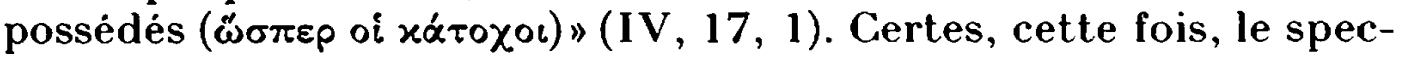
tacle est décrit avec une assez grande précision, mais la façon dont Calasiris met l'accent sur la frénésie des danseurs suggère de sa part une condescendance teintée de réprobation. Et l'on trouve effectivement, un peu plus loin dans le récit, une critique en règle des divertissements vulgaires comme la danse et le chant, à l'occasion du banquet organisé par Chariclès ( $V$, 15, 3 sq.) : celui-ci, en homme soucieux du plaisir de ses hôtes, n'a certes pas négligé de leur offrir les attractions musicales habituelles mais, tandis que les femmes se mettent à danser, il invite ses compagnons à négliger ces distractions trop faciles pour leur préférer le plaisir d'écouter Calasiris, à qui il déclare : "Le récit de tes voyages serait, si tu le voulais, un excellent divertissement pour les convives, plus agréable que toutes les danses et les musiques» $(\mathrm{V}, 16,2)$. Sur quoi Cnémon surenchérit en louant vivement son hôte de leur adresser cette proposition : "Sois béni [...]. Tu avais fait venir, pour égayer le banquet, toute sorte d'instruments de musique, et voici que tu les laisses de côté et te détournes de ces vulgaires plaisirs, impatient d'ètre initié aux mystères d'une existence dont le récit est un divin plaisir" $(\mathrm{V}, 16,3)$. La prédilection exprimée ici pour les charmes de la conversation - prédilection formulée sur un mode ostensiblement platonicien ${ }^{24}$ - rappelle évidemment de fort près les prises de position de Platon sur ce que doit être un banquet de sages ${ }^{25}$, et contribue à accentuer la couleur discrètement philosophique des Éthiopiques.

Mais si Héliodore donne ouvertement congé à la dimension spectaculaire du banquet, les autres romanciers ne s'attardent

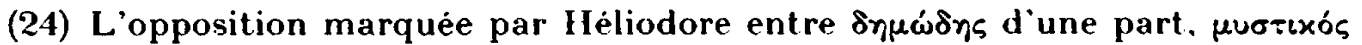

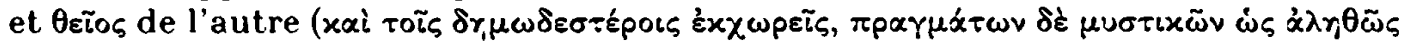

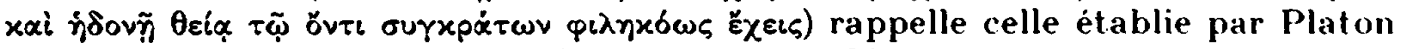

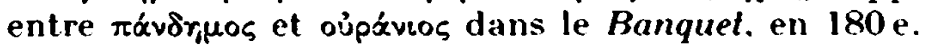

(25) Prolagoras, 374 d : "Quand des gens cultivés se réunissent pour boire, on ne voit auprès d'eux ni joueuses de flùte, ni danseuses. ni citharistes : ils suffisent par eux-mèmes à l'entretien sans avoir besoin d'ajouter à leur propre voix le secours emprunté de tout ce caquet dénué de sens et, mème en buvant largement, ils savent parler et écouter tour à tour avec décence et dignité." 
guère, eux non plus, à décrire spectacles de danses ou prestations musicales, sans doute parce qu'ils sont peu soucieux de realia et peu intéressés par la dimension matérielle du symposium $^{26}$. Seul Longus fait exception en évoquant longuement les chants et danses qui agrémentent le banquet champètre organisé pour fêter la libération de Chloé : il décrit successivement le récital de flûte donné par Philétas (I I, 35, 3-4), la danse de pressoir interprêtée par Dryas $(I I, 36)$ et la pantomime à laquelle se livrent Daphnis et Chloé imitant l'histoire de Pan et de la Nymphe Syrinx (II, 37). Mais cette série de descriptions est loin d'avoir valeur purement ornementale : les trois passages cités tournent en effet autour du thème de la mimésis ${ }^{27}$, thème central dans un roman qui ne cesse d'explorer les relations unissant art et nature. Ainsi l'évocation des spectacles offerts au banquet s'intègre-t-elle au sein d'une réflexion sur l'esthétique. Il en est de mème pour l'ekphrasis de cratère sur laquelle Achille Tatius ouvre sa deuxième scène de symposium. De cet ustensile du banquet, le texte souligne en effet les particularités illusionnistes : c'est un vase orné de grappes de raisin en cristal. qui paraissent vertes tant que le récipient reste vide, et semblent mùrir au fur et à mesure qu'on l'emplit de vin (I I, 3, 1-2). Comme les descriptions de Longus, cette brève ekphrasis est en étroite connexion avec la thématique d'ensemble du roman, dont le cratère fait figure d'emblème, en jouant de ces faux-semblants qui sont une des caractéristiques majeures de Leucippé et Clitophon.

Toutefois. ces deux cas exceptés, la part du spectacle est faible dans les scènes de banquets romanesques. Il n'est pourtant pas rare que les romanciers cherchent à étonner le lecteur, lorsqu'ils évoquent des symposia. Mais c'est par le biais des jeux du paradoxe que se voit réintroduite. subrepticement. la dimension "spectaculaire", ou du moins remarquable. Ainsi Chariton se plait-il à exploiter le motif du banquet qui tourne au drame et se transforme en son contraire, en tableau daffliction et de désolation. Car les symposia sont souvent chez lui le lieu des mau-

(26) Chariton, évoquant en IV. 5, 7 le banquet magnifique donné par Dionysios à ses concitoyens, se contente de mentionner en passant "les accents de la fute" et "les chants mélodieux" qui agrémentent le symposium.

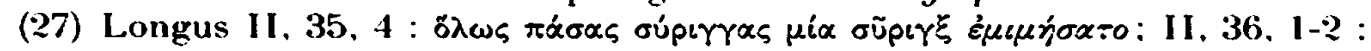

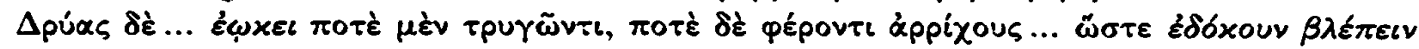

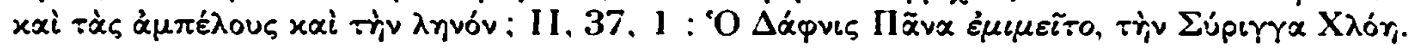


vaises nouvelles ${ }^{28}$ : c'est au cours d'un festin que Chairéas apprend le remariage de Callirhoé, et les lamentations pitoyables auxquelles se livre alors le héros suscitent la compassion générale, si bien que le banquet précédemment qualifié de "réception fort agréable où tout concourait à la joie" (IV, 3,7$)$ se transforme "en une scène de mélodrame" (IV. 3,11: xai

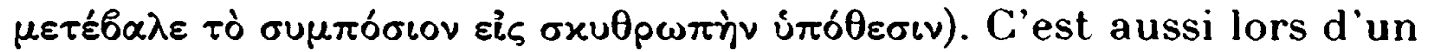
symposium que Dionysios découvre que Chairéas, supposé mort, est toujours en vie : comprenant la menace qui pèse sur son union avec Callirhoé, il perd connaissance - ce qui, assez naturellement, suscite l'affolement des invités, qui ne tardent pas à se.disperser. Et Chariton de conclure : "Le banquet prit fin bien tristement ( $\sigma x \nu \theta \rho \omega \pi \tilde{\omega} \varsigma \delta\left\llcorner\varepsilon \lambda u \theta_{\gamma_{1}}\right)$ : le spectacle de l'évanouissement avait saisi les convives" (IV, 5,10$)$. Héliodore exploite le même motif un peu différemment, puisqu'en $V, 33,4$, c'est non pas l'arrivée d'un malheur inattendu, mais le talent de conteur de Calasiris, trop habile à émouvoir son auditoire, qui transforme le

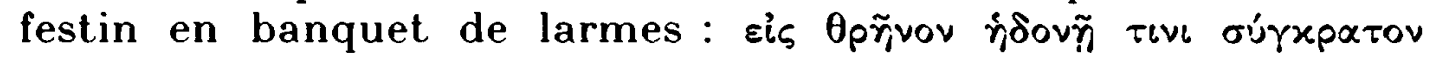

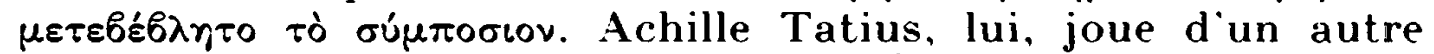
paradoxe : évoquant le repas offert à Éphèse pour célébrer les retouvailles des héros, il le dépeint d'abord comme un banquet

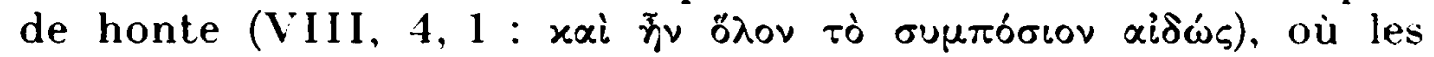
convives n'osent pas se regarder ni se parler, et où seule l'action libératrice du vin viendra susciter les explications qui lèveront enfin la gêne générale.

Pareil goût pour les "banquets à rebours" témoigne de l'influence exercée sur nos romanciers par l'esprit de la seconde sophistique. Mais, de toutes les scènes de symposia présentes dans les romans grecs, c'est sans doute celle où Héliodore dépeint un banquet barbare tournant à la rixe qui est le plus marquée des couleurs de la rhétorique. Car en décrivant ce banquet qui dégénère en massacre, Héliodore a voulu, à n'en pas douter, composer un morceau de bravoure - morceau conçu sous forme de diptyque, dont le premier volet constitue l'ouverture du roman (I, 1, 4 sq.), à quoi répond la fin du récit de Calasiris à Cnémon, consacrée à l'évocation du même épisode ( $V$, 28 sq.). La description de ce symposium barbare s'ouvre en ces termes : "On voyait [...] mèlés les restes pitovables d'un festin

(28) Motif imité par Xénophon d'Éphèse en III, 9, 2-8 : Habrocomès apprend la (fausse) mort d'Anthia au cours d'un repas avec les brigands. 


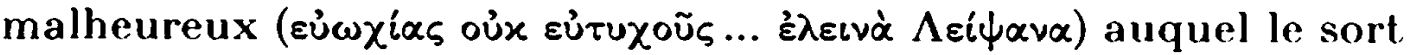
avait réservé ce triste dénouement» $(I, 1,4)$. La suite du texte

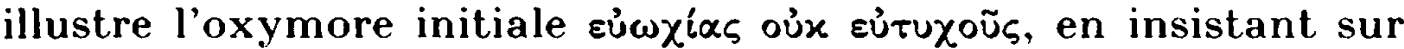
l'étrange juxtaposition des instruments du plaisir (tables, cratères) et des marques du carnage, et en soulignant la façon dont les convives barbares ont détourné de leur fonction normale tous les objets du banquet: "La soudaineté de l'attaque les avait poussés à employer les coupes à un nouvel usage, et à s'en faire des armes de trait" (ibid.). Fait notable, ce banquet barbare est le seul des symposia romanesques qui soit décrit comme un tableau : "Infiniment varié était le spectacle que sur cet espace

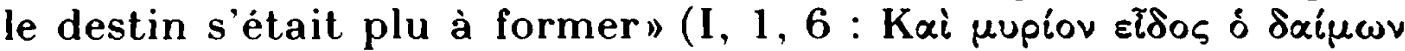

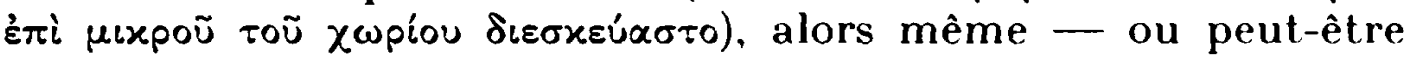
précisément parce que - il s'agit d'un banquet qui n'en est plus un. II n'est pas sans analogie avec le festin "de Lapithes" décrit par Lucien, qui peut-être a servi de modèle à notre romancier ${ }^{29}$. Cette rencontre de Lucien et d'Héliodore confirme en tout cas les tendances sophistiques d'un auteur dont on a vu précédemment qu'il était aussi le plus "philosophe» des romanciers grecs. La chose n'a rien de surprenant, car les échanges entre rhétorique et philosophie sont monnaie courante dans l'Antiquité tardive ${ }^{30}$, et les scènes de banquets romanesques offrent à leur modeste manière une illustration de ces fréquents échanges entre les deux domaines.

Ln rapide regard sur les romans byzantins $d u$ xil" siècle. fidèle imitation des textes de l'époque impériale, suffit à confirmer le caractère topique des scènes de banquets du roman antique : car on assiste dans les œuvres byzantines à une prolifération de symposia - preuve que les Byzantins voyaient bien là un ingrédient constitutif du genre, au mème titre que les scènes de tempêtes ou les fausses morts. Ainsi peut-on dénombrer dans le roman d'Eustathe Macrembolite ${ }^{31}$ une douzaine de banquets,

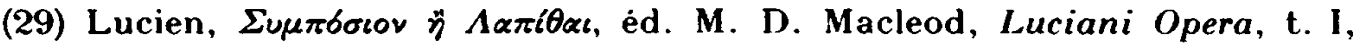
Oxford, 1972, p. 144-163.

(30) Cf. L. Pernot, La rhétorique de l'éloge dans le monde gréco-romain. Paris. 1993, p. 493-605: "L'éloge en question".

(31) Éd. I. Hilberg, Eustathii Macrembolitae, De Hysmines et Hysminiae amoribus, Vienne, 1876. Traduction Fl. Meunier, Les amours homonymes, La roue à

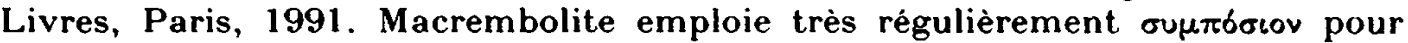
qualifier les banquets qu'il met en scène; les seuls passages où le terme n'apparaît pas sont : VI, $15,1-2$; VIII, 8, 2-3; VIII, 11,4-15, 2 et 20-2I; XI, 2-17, 1 et 18, 2-19, encore s'agit-il dans la plupart des cas de situations limites. 
dont certains évoqués de manière fort circonstanciée. Le texte s'ouvre avec une série de trois repas offerts en l'honneur du protagoniste Hysminias, envoyé comme héraut de Zeus dans la cité d'Aulicomis, où il s'éprend de la fille de son hôte (I, 7-11; II, 12-13; III, 10, 1-IV, 2, 1). Ces trois repas, imités d'Achille Tatius, scandent le développement de l'intrigue amoureuse, comme les trois banquets initiaux du roman antique ${ }^{32}$, mais Macrembolite surenchérit sur son modèle en doublant les scènes de banquets vécues de scènes oniriques où Hysminias revit, sur le mode fantasmatique, les moments qui l'ont tant troublé pendant la journée (III, 4, 2-7 : rêve éveillé ; I I I, 5, 1-6 : sommeil). Aux trois symposia d'Aulicomis font pendant trois autres festins donnés par les parents du héros, lorsque celui-ci revient dans sa patrie escorté de ses hôtes $(\mathrm{V}, 9,2-13,1 ; \mathrm{VI}, 1,2-5,1$; VI, 15, 1-2). Victime de revers de fortune, Hysminias devient ensuite esclave, et son maître à son tour est envoyé en ambassade sacrée, ce qui donne lieu à une nouvelle série de quatre banquets, qui sont pour Hysminias la source de souvenirs nostalgiques, mais vont aussi lui donner l'occasion de retrouver Hysminé, dont il était séparé (IX, 3-4; IX, 7,2-11, 1; IX, 16$21,1 ; X, 7-8)$. S'ensuivent deux festins de retrouvailles, à quoi succède le banquet de noces des héros, qui forme le finale du roman $(X, 16-18,1 ; X I, 2-17,1 ; X I, 18,2-19)$. A cette liste on pourrait encore ajouter quelques cas plus litigieux de quasi-banquets : deux festins barbares marqués par la violence et le

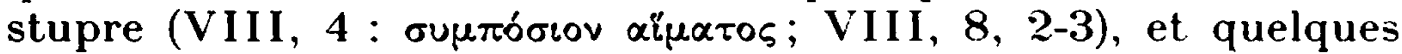
repas servis par Hysminias à ses maîtres, lorsqu'il est réduit en esclavage (VIII, 11,4-15,2; VIII, 20-21). En fait, les scènes de banquets se sont tellement développées et multipliées dans le roman de Macrembolite qu'elles finissent par occuper l'essentiel de l'espace narratif, et par former l'ossature même du texte particularité sans doute à mettre en relation avec la part prépondérante accordée par Macrembolite à l'analyse psychologique, qui chez lui prend largement le pas sur les péripéties.

Si les symposia sont en nombre plus réduit dans les romans de Théodore Prodrome et de Nicétas Eugénianos ${ }^{33}$, la place qui

(32) On retrouve chez Macrembolite, comme chez son modèle antique. les deux motifs de la consommation oculaire (III, 5, 2) et de l'échange des coupes $(\mathrm{V}, 10,3-5 ; 11,2-6 ; 12,2-4)$.

(33) Editions : M. Marcovich, Theodorus Prodromus, Rhodanthe el Dosicles. Leipzig. Teubner, 1992 ; F. Conca, Nicetas Eugenianus. De Drosillae et Chariclis 
leur est réservée reste néanmoins fort importante. Parmi ces symposia, certains ne se démarquent guère des banquets décrits dans les romans grecs, sinon par le traitement un peu plus développé dont ils bénéficient. C'est le cas du festin auquel assistent, à Rhodes, les héros de Prodrome, Rhodanthe et Dosiclès, conviés à dîner par l'hôte du pilote sur le vaisseau de qui ils ont pris la fuite (II, $49 \mathrm{sq}$.) : comme beaucoup de banquets du roman grec, celui-ci a une dimension érotique assez marquée, car il est prétexte à décrire la passion exclusive de Dosiclès, qui n'a d'yeux, tout au long de la soirée, que pour la beauté de Rhodanthe ${ }^{34}$; mais ce banquet est aussi pour les héros l'occasion de raconter aux autres convives le début de leurs aventures, en une analepse inspirée d'Héliodore (II, 171-485).

Plus originale est l'évocation du symposium offert par le barbare Mistyle à Artaxane, ambassadeur de son ennemi Bryaxas, venu lui transmettre un ultimatum. Car l'accent est mis sur le faste de ce banquet, qui relève de la stratégie dintimidation : Mistyle espère en effet impressionner suffisamment son hôte pour couper court à toutes ses revendications - et ceci en lui faisant croire qu'il possède un pouvoir sans limites sur les êtres et les choses. Le symposium organisé pour Artaxane est donc marqué de tous les prestiges de l'illusionnisme, comme l'an-

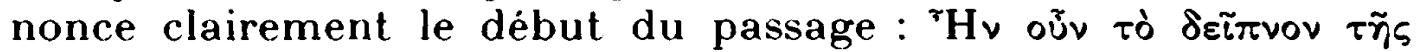

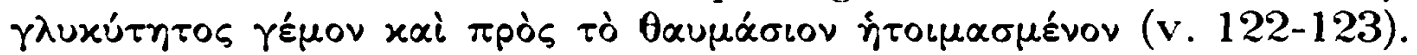
On sert à l'ambassadeur un agneau rôti, dans le ventre duquel

amoribus, Amsterdam, 1990. Chez. Prodrome figurent quatre grandes scènes de

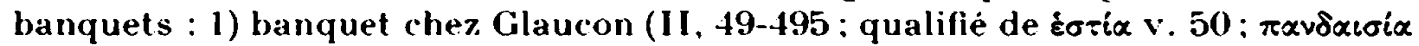

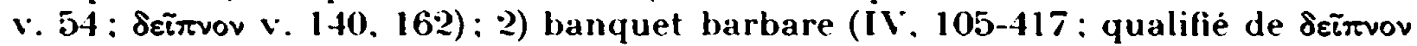

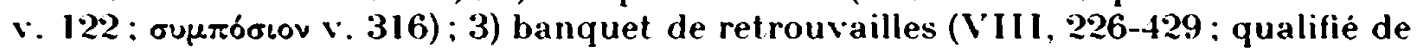

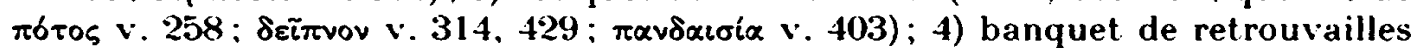

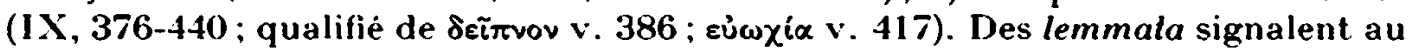
lecteur les deux premiers banquets, sous l“intitulé : $\Delta \varepsilon i \pi v o v ~ \Gamma \lambda \alpha u ́ x \omega v o s$ et $\Delta \varepsilon i \pi v o v$

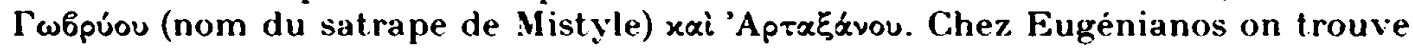
ègalement quatre grandes scènes de banquets : 1) banquet champètre en l'honneur de Dionysos (III, 119-350; qualifiè de $\pi \alpha v \delta \alpha \iota \sigma i \alpha$ v. $291+$ emploi de $\sigma u \mu-$ $\pi 6 \tau$ s v. 204) ; 2) et. 3) repas chez Baryllis (VII, 265-332 et VIII, 243 sq. ; emploi

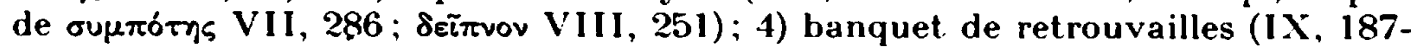

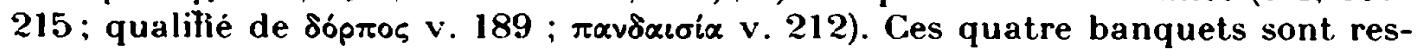

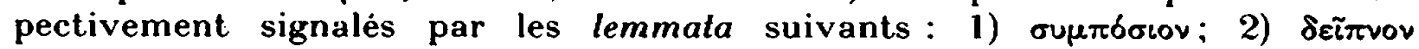

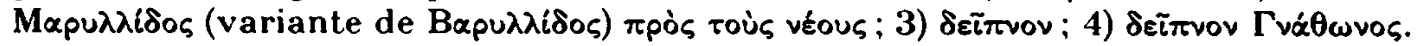

(34) Prodrome brode longuement sur le motif de l'indifférence aux plaisirs du

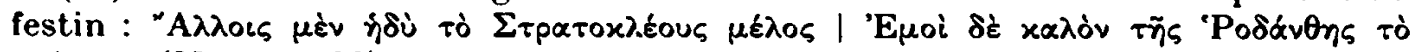
$\sigma \tau \delta \mu \alpha \ldots(11,111-139)$. 
avaient été cousus des oiseaux vivants, qui s'envolent aussitôt la bête découpée - "prodige" dont le naïf barbare se montre vivement frappé (v. $124 \mathrm{sq}$.). On fait venir devant lui un bouffon qui feint de se suicider sous ses yeux, pour ressusciter peu après sur l'ordre de Mistyle — dont il célèbre alors la surnaturelle puissance (v. $214 \mathrm{sq}$.). On cherche aussi à éblouir l'ambassadeur de Bryaxas par un grand étalage de vaisselle somptueuse - telle cette coupe illustrée de scènes de vendanges dont le texte décrit longuement la magnificence (IV, 329-413).

Le banquet donné par Mistyle tranche donc assez nettement sur les banquets évoqués dans les romans de l'époque impériale. Au nombre des tendances nouvelles qu'on voit s'y profiler, figure notamment un goût marqué pour les realia (nourriture. et ustensiles du symposium), que les romanciers antiques étaient au contraire plutôt portés à évacuer. Par l'abondance de détails avec laquelle il évoque les raffinements de la table de Mistyle, Prodrome rappelle les descriptions d'un Pétrone. ou d'un Athénée ${ }^{35}$, et son "banquet" barbare ressortit en fait, tout comme les "banquets" de Trimalcion ou du lieutenant d'Alexandre, Karanos, à la catégorie tardive des Deipna, ou "Festins", avatars dégradés des banquets de l'âge classique, où les événements du repas viennent occuper le premier plan et amènent dans leur sillage l'irruption de la trivialité ${ }^{36}$. L'agneau "farci" servi par Mistyle est révélateur de cette filiation nouvelle : car il a son équivalent exact dans le "porcus troianus" dont Trimalcion gratifie ses hôtes ${ }^{37}$, et participe de ce goût pour la cuisine-surprise qui tranforme le festin en spectacle permanent ${ }^{38}$.

(35) «Cena Trimalcionis», Satiricon, chap. 26-78, et Noces de Karanos. Deipnosophistes, èd. Loeb, Londres, 1930, IV, $128 \mathrm{c}-130 \mathrm{~d}$. L'accent est pareillement mis dans les deux textes sur l'ètalage de luxe. l'abondance et la somptuositè des mets offerts aux invités.

(36) Sur la catégorie des deipna : cf. J. Martin. Symposium. Die Geschichte einer literarischen Form. Paderborn. 1931, p. 149-156. Cf. aussi Fl. Dupont, Le plaisir et la loi, du "Banquel * de Platon au "Satiricon", Paris, 1977. III, 1 : "Le Festin comme genre littéraire" (où le Festin est dit issu de la forme Banquet, "détruite de l'intérieur par la parole triviale et la mangeaille», p. 63).

(37) Pétrone Satiricon, 40, 5. Macrobe. Saturnales, III, 13, 13 (éd. J. Willis. Teubner, 1970) explique qu'on appelait pareil plat *porcus troianus * par référence au cheval de Troie - le porc étant rempli d'animaux vivants comme le cheval l'était de guerriers en armes. Chez. Athénée. op. cit.. IV. 129 b-c. il est aussi question d'un porc farci de $\pi \circ \lambda \lambda \tilde{\omega}_{\nu} \dot{\alpha} \gamma \alpha \theta \tilde{\omega} v$ : grives, canards, bec-figue, huîtres, etc., mais cette fois les animaux sont cuits.

(38) Il est possible qu'en évoquant les mets sophistiqués servis par Mistyle. Prodrome prètende illustrer la truphê barbare du personnage - témoignant 
Il est un autre trait par lequel le banquet barbare de Prodrome se démarque des symposia du roman grec et se rapproche des dîners satiriques à la Pétrone : c'est la présence, en cette scène, d'une dimension nettement comique. Le grotesque fait en effet partie intégrante des Festins, comme l'atteste la bouffonnerie de la Cena Trimalcionis ou du "banquet de Lapithes" par Lucien ${ }^{39}$. Prodrome s'inscrit dans la même lignée en tournant ostensiblement en ridicule la crédulité de l'ambassadeur Artaxane, qu'il montre mystifié par les trucages grossiers de son hôte au point de sombrer dans la terreur la plus complète (IV, $209 ; 213$ ) ; et ce n'est pas un hasard si le bouffon qu'il met en scène s'appelle Satyrion, à l'instar du bouffon de Lucien, auquel sa physionomie aussi l'apparente fortement ${ }^{40}$. Or, ce banquet comique n'est pas un cas isolé dans le corpus des romans byzantins: on retrouve la même veine bouffonne au livre VII du roman d'Eugénianos (disciple de Prodrome), dans l'évocation du festin offert par la vieille paysanne Baryllis aux héros, Drosilla et Chariclès, qui viennent de se retrouver (v. 265 sq.) : un long

ainsi d'une distance critique comparable à celle de Pétrone. En revanche. la description faite par Macrembolite dartifices culinaires du mème genre. dans une scène de festin purement "grec", rappelle bien davantage l'admiration béated'un Athénée : $O$ n apporte de nouveaux plats sur la table, pas seulement du gibier, du poisson comme sait s'en régaler un habitant du littoral ou du continent, mais des mets plus compliqués préparés avec art par les cuisiniers : du poisson présenté comme du gibier, du paon comme du poisson - le texte grec est à vrai dire un peu plus énigmatique que ne le laisse supposer la traduc-

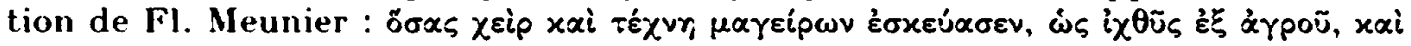

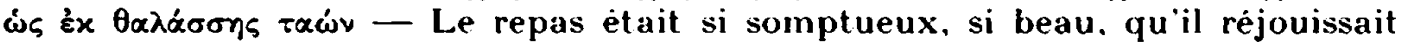
autant les yeux que le palais" (II, 13,1). On songe au passage des Deipnosophistes évoquant les faux anchois préparés, pour satisfaire une envie du roi Vicomède de Bithynie, au moyen de lamelles de rave macérées dans l'huile et saupoudrées de grains de pavot (I. $7 \mathrm{~d}-\mathrm{f}$ ). Si pareils exemples de cuisine mimétique abondent dans le Satiricon et si Trimalcion vante l'aptitude de son cuisinier Dédale à métamorphoser tout ce qu'il touche (" $A$ votre choix, avec une vulve il fait un poisson, avec du lard une palombe, avec un jambon une tourterelle, avec un jambonneau une poule" chap. 70,2$)$, le texte est évidemment ironique.

(39) Sur la dimension comique des "Festins", cf. J. Martin, qui définit les deipna comme des symposia geloia, où s'èpanouit l'élément bouffon déjà présent dans le banquet platonicien avec le hoquet. d'Aristophane ou l'ivresse d'Alcibiade, op. cit., p. 311.

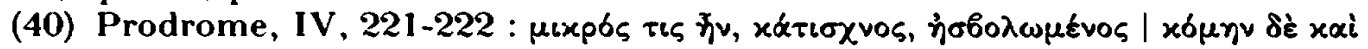

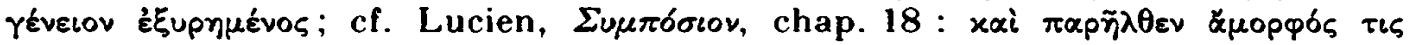
Ě 
passage de cette scène est en effet consacrè à décrire la danse que Baryllis, réjouie du bonheur de ses hôtes, interprète en leur honneur - prestation périlleuse vu l'âge avancé de la danseuse, et qui s'achève en une chute ridicule - ce qui déclenche l'hilarité des jeunes convives peu charitables (v. 276-308) ${ }^{41}$. Si pareils tableaux nous emmènent bien loin des symposia idéalistes du roman grec, on ne saurait pourtant parler sans exagération d'innovation byzantine, car l'inflexion nouvelle prise par les scènes de banquets dans l'œuvre des "épigones" tient pour une large. part à l'influence de modèles littéraires autres, venus apporter à des épisodes imités du roman antique une touche hétérogène.

Plus original apparait en revanche un autre trait présent dans plusieurs scènes de banquets $\mathrm{du} \mathrm{XII}^{\mathrm{e}}$ siècle : il s'agit des préoccupations morales exprimées par les romanciers byzantins, qui paraissent parfois prendre les symposia comme prétexte à développer la question de la vertu féminine. De fait, les exigences morales en ce domaine se sont durcies depuis l'Antiquité tardive, période de relative émancipation, et la présence des femmes au banquet paraît poser problème aux écrivains byzantins plus qu'à leurs prédécesseurs antiques ${ }^{42}$. Ainsi Prodrome

(41) Cf. Athénée évoquant la danse interprétée par le bouffon Mandrogénès et son épouse de plus de quatre-vingts ans lors des noces de Karanos (IV. 130 c $^{\circ}$ : mais Eugénianos s'attarde complaisamment à souligner les détails scabreux de la scène et fait grand usage de ce que E. R. Curtius appelle le "thème du $\pi \rho \omega x$ tòs $\lambda \alpha \lambda \tilde{\omega} v »$ in La litterature europeenne et le Moyen Àge latin, t. II, p. 215. èd. PL:F Agora, 1956.

(42) Sur les usages des Byzantins en matière de repas et banquets, cf. Ph. Koukoulès, Byzantinôn Bios kai Politismos, t. V, thènes, 1952, p. 136-205:

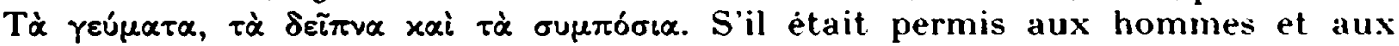
femmes de manger ensemble à l'occasion des repas de famille. et si la chose n'était pas jugée répréhensible, à condition que ces repas fussent dépourvus d'attractions spectaculaires comme chants, musique et danse, tenus pour "sataniques" (cf. le vingt-deuxième canon du concile de Vicée II - ou septième concile œcuménique, annèe 787 - in Les conciles æcuméniques, sous la direction de G. Alberigo, Paris, 1994, t. II, 1 : Les décrets, p. 342-343), il était en revanche fort mal perçu qu'une femme participe à des banquets, et la cent dix-septième Novelle de Justinien (année 542) autorisait mème la répudiation. au cas où une femme aurait, contre la volonté de son mari. festoyé avec des

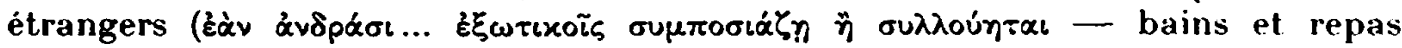
communs étant considèrés comme deux fautes également graves - cf. K. E. Zachariä von Lingenthal, Imperatoris Justiniani Novellae quae vocanlur. Leipzig, 1881, t. II, p. 218). Mème au palais impérial, hommes et femmes mangeaient séparément lors des réceptions officielles, comme le montre l'étiquette suivie lors du séjour de l'impératrice russe Olga à Constantinople à l'automne 
insiste-t-il sur les scrupules de Rhodanthe à se rendre au banquet de Glaucon; elle commence par refuser d'entrer et prend Dosiclès à témoin de ses craintes : "Comment donc, Dosiclès, pourrais-je franchir la porte et manger en compagnie de tant d'hommes, moi qui suis la seule femme?"(I I, 74-75). Et Dosiclès, qui admire la réserve de la jeune fille, ne parvient à vaincre ses préventions qu'en lui faisant valoir qu'ils sont en fait invités par une femme, Myrtipnoé, l'épouse de Glaucon.

Chez Macrembolite, visiblement intéressé lui aussi par la question de la vertu féminine, le problème est posé en termes plus ambigus, pour ne pas dire énigmatiques. L’intrigue amoureuse évoquée dans Hysminé et Hysminias présente en effet la particularité majeure de montrer l'héroïne prenant l'initiative de séduire le héros, et ce sont précisément les banquets offerts par son père en l'honneur d'Hysminias qui servent de champ aux premières avances de la jeune fille, celle-ci profitant du ròle d'échanson qui lui est échu pour multiplier les signes à l'adresse d'Hysminias qui, en héros chaste et naïf, commence par se montrer fort choqué de la chose $(I, 9,1 \text { et } 3 ; 1 I, 12,2)^{43}$. On peut

957 : celle-ci dine en effet avec la bassilissa et les princesses, tandis que l'empereur reçoit à sa table les hauts dignitaires et parents de sa visiteuse (cf. Constantin Porphyrogénète, De Cerimoniis Aulae Byzantinae, II, 15, èd. I. Reiske. CSHB, Bonn, 1829, p. 596, 20-597, 10 et 598, 3-8). La méfiance que suscite la présence des femmes aux repas et lidée quelles trouvent là prétexte à inconduite, sont bien illustrées par le motif du moine en butte aux avances de la

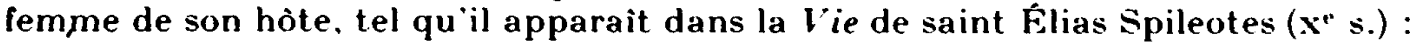

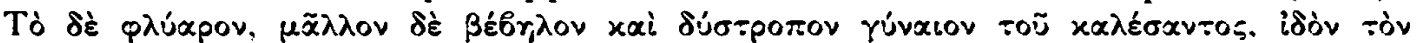

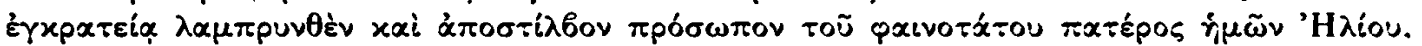

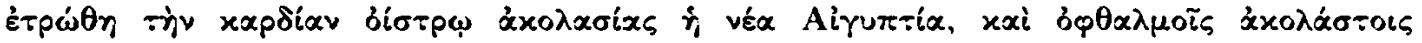

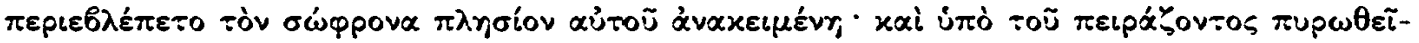

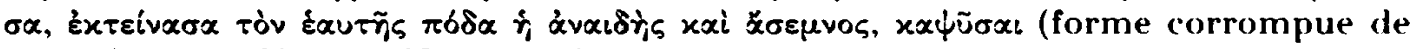

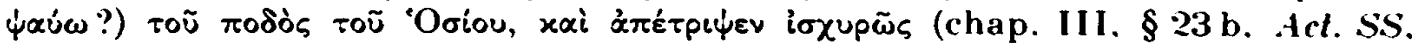
Sept. III. p. 857, accentuation rectifiée).

(43) Le comportement attribué à Hysminé lors des deux premiers banquets est le comportement type d'une fille éhontée : elle se dénude les bras — Clément d'Alexandrie, dans ses Conseils aux femmes sur la manière de se tenir à table. insiste tout particulièrement sur le danger de pareille attitude : "Il ne faut en aucune manière permettre aux femmes de découvrir et de montrer quoi que ce soit de leur corps. de peur que les uns et les autres ne tombent dans le mal : les hommes parce qu ils sont excités à regarder, et les femmes parce qu elles veulent attirer sur elles les regards des hommes». Le Pédagogue. II, chap. 2. 33, 4. SC 108, Paris, 1965 — ; elle chuchote à l'oreille d'Hysminias et lui presse le pied sous la table, exactement comme le faisait la femme de l'hòte dans la lie de

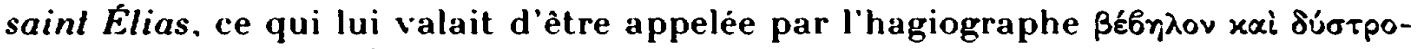

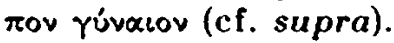


s'interroger sur le sens qu'il convient d'attribuer à pareille mise en scène. Macrembolite veut-il seulement jouer avec la tradition en inversant les rôles traditionnels du héros et de l'héroïne? prétend-il suggérer, à travers cet épisode, le danger que des pratiques comme le banquet font peser sur la vertu des femmes, aisément sujettes à la tentation? ou s'amuse-t-il à "faire exotique" et, puisque son roman est une œuvre à l'antique, ayant pour cadre la Grèce classique, s'attache-t-il à peindre en Hysminé la liberté morale de l'Antiquité païenne, telle que pouvait la fantasmer un public soumis à la pression d'une orthodoxie rigoriste ${ }^{44}$ ? Il n'est pas facile de répondre, et la suite du récit n'aide guère à trancher la question : car une fois Hysminias séduit, Hysminé reprend le rôle de vierge réservée habituel aux héroïnes de roman, et le texte insiste à maintes reprises sur son comportement pudique - quoique peut-être non sans malice : il arrive en effet à Hysminias (narrateur du roman) de nommer charmante réserve ce que même un lecteur moderne serait plus enclin à qualifier de rouerie. Les commentaires du héros sur l'exemplaire décence de sa bien-aimée ne sont d'ailleurs pas dépourvus d'ambiguïté, et l'on se demande parfois si c'est la retenue de la jeune fille qu'il admire ou ses talents de simulatrice. Ainsi loue-t-il, dans la quatrième scène de banquet, l'apparence pleine de modestie observée par Hysminé, alors qu'elle se livre avec lui, à l'insu de ses parents, au jeu amoureux de la coupe partagée : "Comme il se doit pour une jeune fille ( $x<\tau \dot{\alpha}$

(44) Sur l'image (fort abusive) que les Byzantins se faisaient de la "liberté grecque », cf. le commentaire d'Aréthas de Césarée aux chapitres 8-9 du Banquel de Lucien (où il est précisé que les femmes viennent occuper la rangée de lits placée à droite de l'entrée, tandis que les hommes s'installent en face d'elles) :

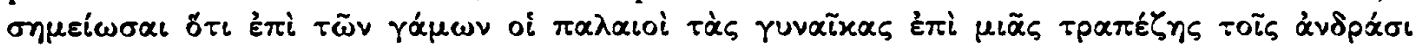

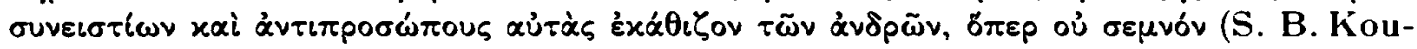

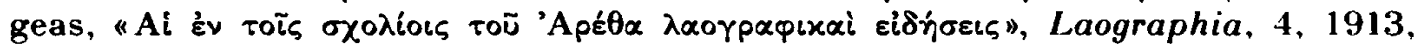
p. 258). Eustathe de Thessalonique, à propos des vers $328 \mathrm{sq}$. du chant I de l'Odyssée, souligne de mème la présence de Pénélope au banquet des prétendants - quoique à la différence d'Aréthas, il ne marque pas explicitement sa désap-

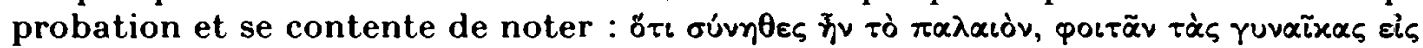
$\tau \dot{\alpha} \tau \tilde{\omega} v \alpha \dot{\alpha} v \delta \rho \tilde{\omega} v \sigma u \mu \pi \delta ́ \sigma i \alpha$. Mais le fait lui paraît assez remarquable (et assez choquant?) pour qu'il prenne soin de mentionner, en parallèle au cas de Pénélope, celui d'Hélène au chant IV, d'Aréthé et Nausicaa au chant VIII, et pour qu'il attire l'attention sur les précautions pudiques prises par l'épouse d'Ulysse, qui se

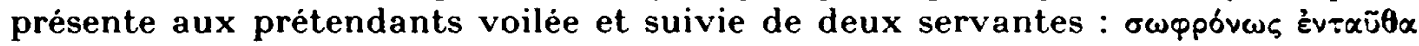

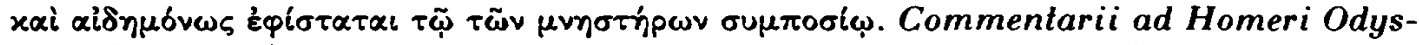
seam $(1420,56)$, Leipzig, J. A. G. Weigel, 1825-1826, t. I, p. 63. 
$\pi \propto \rho \theta \varepsilon ́ v o v)$, elle prend la coupe du bout des doigts, en approche ses lèvres avec une délicatesse virginale $(\pi \alpha p \theta \varepsilon v \iota x \tilde{\omega} \varsigma)$, goûte à peine le vin et rend la coupe pleine, secondée dans son rôle par sa

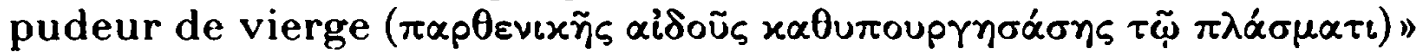
(V, 11, 2; trad. modifiée). Et si, lors du banquet suivant, Hysminias fait valoir la pudeur avec laquelle Hysminé lui adresse à la dérobée un signe de bienvenue, son approbation semble aller beaucoup plus aux manières de la jeune fille qu'à ses qualités morales : "Elle me rend mon salut d'un discret signe de tête, avec toute la réserve qui convient à une jeune fille (ís cixós... $\pi \alpha p \theta \varepsilon v u x \tilde{\omega} s)$ " (VI, 1,3). On pourrait donc être tenté de voir en ces éloges assez hypocrites un bel exemple de la duplicité familière aux Byzantins en matière de morale ${ }^{46}$, mais il n'en est pas moins vrai qu'en dépit de ses hardiesses initiales, Hysminé reste vierge jusqu'à la fin du roman, et les deux banquets de retrouvailles sont à nouveau pour le romancier l'occasion d'évoquer de manière insistante la pudeur dont la jeune fille fait preuve sous le regard accusateur de son père ${ }^{46}$ : "Pleine de honte, Hysminé gardait les yeux baissés et ne touchait même pas du bout des doigts à la nourriture" $(X, 16,1)$. Elle commence par refuser de prendre la parole pour raconter ses aventures : "La pudeur

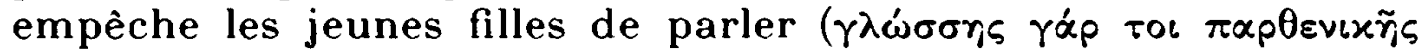
$\alpha i \delta \dot{c} s \pi p o x \alpha \dot{\theta} \theta \eta \tau \alpha)$. Je ne serai pas assez effrontée pour ne pas trembler devant mon père, ni oser défier ma mère. Le silence et

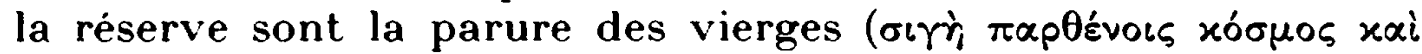

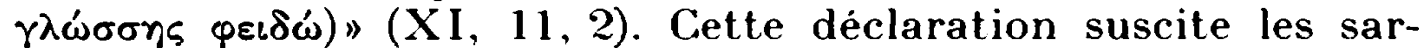
casmes de Sosthénès, qui reproche à sa fille de faire un peu tardivement étalage de pudeur, après avoir par son comportement

(45) Cf. C. H. Beck, Byzantinisches Erotikon, München, 1986 (notamment p. 211, où Beck parle de "Doppelleben").

(46) On pourrait également citer, pour illustrer l'importance accordée à la thèmatique de la vertu féminine dans les scènes de banquets du roman de Macrembolite, un autre épisode, évoquant les précautions prises par les parents de la jeune Rhodopé, dont Hysminé est devenue la servante, pour que leur fille puisse participer à un symposium sans que sa pudeur ait à subir la moindre

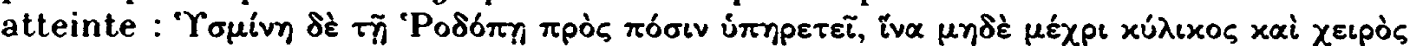

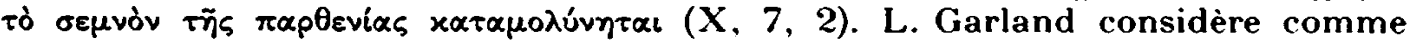
caractéristique de l'univers romanesque byzantin le mélange, pour nous assez déconcertant, de valorisation quasi obsessionnelle de la virginité et de goùt marqué pour l'érotisme (in "Be Amourous, But Be Chaste. Sexual Morality in Byzantine Learned and Vernacular Romance", Byzantine and Modern Greek Studies 14, 1990, 62-120). 
enfreint toutes les règles de la bonne conduite, et la discussion rebondit encore avec l'intervention de l'hôte, prêtre d'A pollon, qui objecte à Sosthénès que ce sont les reproches essuyés et non les fautes commises qui provoquent la honte d'Hysminé. Si donc on compare toute cette séquence du roman de Macrembolite aux passages d'Achille Tatius dont elle s'inspire (VIII, 4-7,2 et VIII, 15,3-18), on constate entre les deux auteurs un écart assez considérable. Car le romancier grec, dans ses banquets de retrouvailles, ne mentionnait que très fugitivement la honte éprouvée par Hysminé en présence de son père ${ }^{47}$; Macrembolite a développé ce qui, chez son modèle, restait à l'état de notation incidente, pour en tirer prétexte à instaurer entre ses personnages un véritable débat moral sur la question de la vertu débat dont le banquet est à la fois le cadre et l'occasion.

C'est sur la notion même de topos que je voudrais conclure : car la manière sensiblement différente dont les romanciers grecs et byzantins traitent le motif du banquet prouve, me semblet-il, à l'évidence, que les lieux communs ne sont pas, quoi qu'on ait pu prétendre, matière inerte et vide de sens. Sans doute les œuvres littéraires qui se nourrissent de stéréotypes donnentelles souvent à première vue une impression de permanence et de répétitivité qu'on peut juger lassante, mais cette impression se révèle vite trompeuse à qui accepte d'y regarder de plus près : loin d'être un poids mort, charrié de textes en textes au fil des siècles, et justifié par le seul fait d'un culte obstiné du passé, les stéréotypes évoluent eux aussi à leur maniêre furtive, et la fréquence, les conditions mêmes de leur emploi, les éventuels déplacements d'accent auxquels ils sont soumis sont autant de subtils indices signalant, chez ceux qui en font usage, des orientations et des choix nouveaux.

Corinne Jounno, Université de Caen.

(47) AT VIII, 4, 1 : "Leucippé, la plupart du temps regardait à terre" + VIII, 15, 3 : "Leucippé, comme elle n'avait plus honte devant son père. puisqu'elle avait été reconnue vierge, raconta avec plaisir ses mésaventures." 